Journal of Mathematics and Statistics 5 (4): 342-347, 2009

ISSN 1549-3644

(C) 2009 Science Publications

\title{
Greatest Common Divisor and Least Common Multiple Matrices on Factor Closed Sets in a Principal Ideal Domain
}

\author{
${ }^{1}$ A.N. El-Kassar, ${ }^{2}$ S.S. Habre and ${ }^{3}$ Y.A. Awad \\ ${ }^{1}$ Lebanese American University, P.O. Box 13-5053, \\ Chouran-Beirut, 1102 2801, Lebanon \\ ${ }^{2}$ Lebanese American University, Lebanon \\ ${ }^{3}$ Lebanese International University, Lebanon
}

\begin{abstract}
Problem statement: Let $\mathrm{T}$ be a set of $\mathrm{n}$ distinct positive integers, $\mathrm{x}_{1}, \mathrm{x}_{2}, \ldots, \mathrm{x}_{\mathrm{n}}$. The $\mathrm{n} \times \mathrm{n}$ matrix [T] having $\left(x_{i}, x_{j}\right)$, the greatest common divisor of $x_{i}$ and $x_{j}$, as its $(i, j)$-entry is called the greatest common divisor (GCD) matrix on $T$. The matrix $[[T]]$ whose $(i, j)$-entry is $\left[x_{i}, x_{j}\right]$, the least common multiple of $x_{i}$ and $x_{j}$, is called the least common multiple (LCM) matrix on T. Many aspects of arithmetics in the domain of natural integers can be carried out to Principal Ideal Domains (PID). In this study, we extend many recent results concerning GCD and LCM matrices defined on Factor Closed (FC) sets to an arbitrary PID such as the domain of Gaussian integers and the ring of polynomials over a finite field. Approach: In order to extend the various results, we modified the underlying computational procedures and number theoretic functions to the arbitrary PIDs. Properties of the modified functions and procedures were given in the new settings. Results: Modifications were used to extend the major results concerning GCD and LCM matrices defined on FC sets in PIDs. Examples in the domains of Gaussian integers and the ring of polynomials over a finite field were given to illustrate the new results. Conclusion: The extension of the GCD and LCM matrices to PIDs provided a lager class for such matrices. Many of the open problems can be investigated in the new settings.
\end{abstract}

Key words: GCD matrix, lcm matrix, factor-closed sets, principal ideal domain

\section{INTRODUCTION}

Let $\mathrm{T}=\left\{\mathrm{x}_{1}, \mathrm{x}_{2}, \ldots, \mathrm{x}_{\mathrm{n}}\right\}$ be a set of $\mathrm{n}$ distinct positive integers. The $n \times n$ matrix $[\mathrm{T}]$ having $\left(\mathrm{x}_{\mathrm{i}}, \mathrm{x}_{\mathrm{j}}\right)$, the greatest common divisor of $\mathrm{x}_{\mathrm{i}}$ and $\mathrm{x}_{\mathrm{j}}$, as its $(\mathrm{i}, \mathrm{j})$-entry is called the Greatest Common Divisor (GCD) matrix on T. The matrix $[[\mathrm{T}]]$ whose $(\mathrm{i}, \mathrm{j})$-entry is $\left[\mathrm{x}_{\mathrm{i}}, \mathrm{x}_{\mathrm{j}}\right]$, the least common multiple of $\mathrm{x}_{\mathrm{i}}$ and $\mathrm{x}_{\mathrm{j}}$, is called the least common multiple (LCM) matrix on $\mathrm{T}$. The set $\mathrm{T}$ is said to be factor closed (FC) if it contains every divisor of $\mathrm{x}$ for any $\mathrm{x} \in \mathrm{T}$. In $1876, \mathrm{Smith}^{[11]}$ showed that the determinant of the GCD matrix [T] on a FC set T is the product $\prod_{\mathrm{i}=1}^{\mathrm{n}} \varphi\left(\mathrm{x}_{\mathrm{i}}\right)$, where $\varphi$ is Euler's totient phifunction. Moreover, Smith considered the determinant of the LCM matrix on a FC set and showed that it is equal to the product $\prod_{i=1}^{n} \varphi\left(x_{i}\right) \pi\left(x_{i}\right)$, where $\pi$ is a multiplicative function defined for a prime power $\mathrm{p}^{\mathrm{r}}$ by $\pi\left(p^{r}\right)=-p$. Since then many papers related to Smith's results have been published. Recently, this field has been studied intensively. This new inspiration started in by Beslin and $\operatorname{Ligh}^{[3,4]}$.

$\mathrm{In}^{[3]}$, Beslin and Ligh obtained a structure theorem for GCD matrices and showed that, if $\mathrm{S}$ is FC, then $\operatorname{det}[\mathrm{T}]=\prod_{\mathrm{i}=1}^{\mathrm{n}} \varphi\left(\mathrm{x}_{\mathrm{i}}\right)$. They conjectured that the converse is true. $\mathrm{In}^{[10]}$, Li proved the converse and provided a formula for the determinant of an arbitrary GCD matrix. Beslin and $\operatorname{Ligh}^{[4,5]}$ generalized these results by extending the FC sets to a larger class of sets, gcdclosed sets. $\mathrm{In}^{[1]}$, a structure theorem for [[T]] was obtained from the structure of the reciprocal GCD matrix $1 /[\mathrm{T}]$, the $(\mathrm{i}, \mathrm{j})$-entry of which is $1 /\left(\mathrm{x}_{\mathrm{i}}, \mathrm{x}_{\mathrm{j}}\right)$. Given a FC set T, Bourque and Ligh $^{[6]}$ calculated the inverses of $[\mathrm{T}]$ and $[[\mathrm{T}]]$ and showed that $[[\mathrm{T}]][\mathrm{T}]^{-1}$ is an integral matrix. In that study, they stated their famous conjecture that the LCM matrix on any gcd-closed set is invertible. Bourque and $\operatorname{Ligh}^{[7,8]}$ investigated the structures, the determinants and the inverses associated with classes of arithmetical functions. For a brief

Corresponding Author: A.N. El-Kassar, Lebanese American University, P.O. Box 13-5053, Chouran-Beirut, 1102 2801, Lebanon Tel: 961-1-786456, Ext. 1189 Fax: 961-1-867098 
review of papers relating to Smith's determinant, we refer $\mathrm{to}^{[9]}$. Using the language of posets, the authors gave a common structure that is present in many extensions of Smith's determinants. Beslin and ElKassar $^{[2]}$ extended the results $\operatorname{in}^{[3]}$ to unique factorization domains.

The purpose of this study is to extend many of the recent results concerning GCD and LCM matrices defined on factor-closed sets to arbitrary Principal Ideal Domains (PID) such as the domain of Gaussian integers and the ring of polynomials over a finite field.

\section{MATERIALS AND METHODS}

Let $\mathrm{S}$ be a PID and let $\mathrm{a}, \mathrm{b} \in \mathrm{S}$. We say that $\mathrm{a}$ and $\mathrm{b}$ are associates and write $a \sim b$, if $a=u b$ for some unit element $\mathrm{u}$ in $\mathrm{S}$. If $\mathrm{b}$ is a nonzero nonunit element, then $\mathrm{b}$ has a unique factorization, up to associates, into prime elements in $\mathrm{S}$. That is, $\mathrm{b}=\mathrm{up}_{1}^{\alpha_{1}} \mathrm{p}_{2}^{\alpha_{2}} \ldots \mathrm{p}_{\mathrm{i}}^{\alpha_{\mathrm{i}}}$, where the $\mathrm{p}_{\mathrm{j}}{ }^{\prime} \mathrm{s}$ are distinct primes in $S$. Also, every finite set $\left\{b_{1}, b_{2}, \ldots\right.$, $\left.\mathrm{b}_{\mathrm{n}}\right\}$ admits, up to associates, a greatest common divisor. For a nonzero element $b$ in $S$, define $q(b)$ to $b e|S /\langle b\rangle|$, the order of the quotient ring $S /\langle b\rangle$, where $\langle b\rangle$ is the principal ideal generated by $b$. Note that $q(u)=1$, for any unit $u$. Also note that in $Z$, Z[i] and $Z_{p}[x], q(b)$ is finite $\forall \mathrm{b} \neq 0$. Throughout the following we consider $S$ to be a PID having the property that $\mathrm{q}(\mathrm{b})$ is finite $\forall \mathrm{b} \neq$ 0 . It can be shown that $q(a b)=q(a) q(b)$. Hence, if $\mathrm{b}=\mathrm{up}_{1}^{\alpha_{1}} \mathrm{p}_{2}^{\alpha_{3}} \ldots \mathrm{p}_{\mathrm{i}}^{\alpha_{\mathrm{i}}}, \quad$ then $\mathrm{q}(\mathrm{b})=\left(\mathrm{q}\left(\mathrm{p}_{1}\right)\right)^{\alpha_{1}}\left(\mathrm{q}\left(\mathrm{p}_{2}\right)\right)^{\alpha_{2}} \ldots\left(\mathrm{q}\left(\mathrm{p}_{\mathrm{i}}\right)\right)^{\alpha_{\mathrm{i}}}$. For a positive integer $n, q(n)=n$ and for a Gaussian integer $a+b i, q(a+b i)=a^{2}+b^{2}$. Also, if $f(x)$ is $a$ polynomial of degree $n$ in $Z_{p}[x]$, then $q(f(x))=p^{n}$. Define $\varphi_{\mathrm{s}}(\mathrm{b})=|\mathrm{U}(\mathrm{S} /\langle\mathrm{b}\rangle)|$, the order of the group of units $\mathrm{U}(\mathrm{S} /\langle\mathrm{b}\rangle)$. Then $\varphi_{\mathrm{s}}(\mathrm{b}) \geq 1$ and the equality holds iff $b$ is a unit. Also, $\varphi_{s}(b)=q(p)^{-1}$ iff $p$ is prime in $S$. It can be shown that $\varphi_{s}(b)$ is multiplicative and if $\mathrm{b}=\mathrm{up}_{1}^{\alpha_{1}} \mathrm{p}_{2}^{\alpha_{3}} \ldots \mathrm{p}_{\mathrm{i}}^{\alpha_{i}}$, then:

$$
\begin{aligned}
\varphi_{\mathrm{S}}(\mathrm{b})= & \left(\mathrm{q}\left(\mathrm{p}_{1}\right)-1\right)\left(\mathrm{q}\left(\mathrm{p}_{1}\right)\right)^{\alpha_{1}-1}\left(\mathrm{q}\left(\mathrm{p}_{2}\right)-1\right) \\
& \left(\mathrm{q}\left(\mathrm{p}_{2}\right)\right)^{\alpha_{2}-1} \ldots\left(\mathrm{q}\left(\mathrm{p}_{\mathrm{i}}\right)-1\right)\left(\mathrm{q}\left(\mathrm{p}_{\mathrm{i}}\right)\right)^{\alpha_{\mathrm{i}}-1}
\end{aligned}
$$

Now, if $S=Z$, then $\varphi_{\mathrm{s}}(\mathrm{b})$ becomes Euler's phifunction. Also, if $f(x)=\left(p_{1}(x)\right)^{\alpha_{1}}\left(p_{2}(x)\right)^{\alpha_{2}} \ldots\left(p_{i}(x)\right)^{\alpha_{i}}$ is a polynomial of degree $n$ in $S=Z_{p}[x]$, a product of powers of distinct irreducible polynomials $\mathrm{p}_{\mathrm{j}}(\mathrm{x}), 1 \leq \mathrm{j} \leq$ i, then:

$$
\varphi_{\mathrm{s}}(\mathrm{f}(\mathrm{x}))=\mathrm{p}^{\sum_{\mathrm{k}=\mathrm{I}_{\mathrm{k}}}^{\mathrm{i}\left(\left(_{\mathrm{k}}-1\right)\right.}} \prod_{\mathrm{k}=1}^{\mathrm{i}}\left(\mathrm{p}^{\mathrm{r}_{\mathrm{k}}}-1\right)
$$

where, $p_{j}(x)$ is of degree $r_{j}$. For example, if $f(x)=\left(x^{2}+\right.$ $1)^{4}(x+1)^{4}\left(x^{3}+x^{2}+x+4\right)$ in $S=Z_{2}[x]$, then $\varphi_{s}(f(x))=3^{7}$. $2^{5}$.13. Now, if $\beta=u \beta_{1}^{k_{1}} \beta_{2}^{k_{2}} \ldots \beta_{i}^{k_{i}}$, a product of distinct Gaussian primes $\beta_{\mathrm{j}}=\mathrm{a}_{\mathrm{j}}+\mathrm{i} \mathrm{b}_{\mathrm{j}}, 1 \leq \mathrm{j} \leq \mathrm{i}$, then:

$$
\phi_{s}(\beta)=\prod_{j=1}^{i}\left(a_{j}^{2}+b_{j}^{2}\right)^{k_{j}-1}\left(a_{j}^{2}+b_{j}^{2}-1\right)
$$

For example, if $\beta=6+42 i \sim 3(1+i)^{3}(1+2 i)^{2}$, then $\varphi_{\mathrm{s}}(\beta)=640$.

Let $S$ be a PID and let $T=\left\{t_{1}, t_{2}, \ldots, t_{n}\right\}$ be a set of nonzero nonassociate elements in S. Define a linear ordering $<$ on $T$ according to the following scheme: If $\mathrm{q}\left(\mathrm{t}_{\mathrm{i}}\right)<\mathrm{q}\left(\mathrm{t}_{\mathrm{j}}\right)$ then $\mathrm{t}_{\mathrm{i}}<\mathrm{t}_{\mathrm{j}}$ and if the equality $\mathrm{q}\left(\mathrm{t}_{\mathrm{i}}\right)=\mathrm{q}\left(\mathrm{t}_{\mathrm{j}}\right)$ holds then order $t_{i}$ and $t_{j}$ according to any scheme depending on the given domain $\mathrm{S}$. For instance, if $\mathrm{S}=\mathrm{Z}[\mathrm{i}]$ and $\mathrm{q}\left(\mathrm{t}_{\mathrm{i}}\right)=\mathrm{q}\left(\mathrm{t}_{\mathrm{j}}\right)$, where $\mathrm{t}_{\mathrm{i}} \sim \mathrm{a}+\mathrm{ib}, \mathrm{t}_{\mathrm{j}} \sim \mathrm{c}+\mathrm{id}, \mathrm{a}, \mathrm{b}, \mathrm{c}, \mathrm{d} \geq 0$, then define $t_{i}<t_{j}$ whenever $b<d$. In the case $S=Z_{p}[i]$ and $\mathrm{q}\left(\mathrm{t}_{\mathrm{i}}(\mathrm{x})\right)=\mathrm{q}\left(\mathrm{t}_{\mathrm{i}}(\mathrm{x})\right)$, where $\mathrm{t}_{\mathrm{i}}(\mathrm{x}) \sim \mathrm{x}^{\mathrm{n}}+\mathrm{a}_{\mathrm{n}}{ }^{-1} \mathrm{x}^{\mathrm{n}^{-1}}+\ldots+\mathrm{a}_{1} \mathrm{x}+\mathrm{a}_{0}$, $\mathrm{t}_{\mathrm{j}}(\mathrm{x}) \sim \mathrm{x}^{\mathrm{n}}+\mathrm{b}_{\mathrm{n}}^{-1} \mathrm{x}^{\mathrm{n}^{-1}}+\ldots+\mathrm{b}_{1} \mathrm{x}+\mathrm{b}_{0}, 0 \leq \mathrm{a}_{\mathrm{j}}, \mathrm{b}_{\mathrm{j}} \leq \mathrm{p}-1, \mathrm{j}_{0}$ is the smallest index $j$ such that $a_{j} \neq b_{j}$, then define $t_{i}(x)\left\langle t_{j}(x)\right.$ whenever $a_{j 0}<b_{j 0}$. If the set $T$ is ordered so that $\mathrm{t}_{1}\left\langle\mathrm{t}_{2}\left\langle\ldots\left\langle\mathrm{t}_{\mathrm{n}}\right.\right.\right.$, we say that $\mathrm{T}$ is q-ordered. Two sets $\mathrm{T}$ and $\mathrm{T}^{\prime}$ in $\mathrm{S}$ are associates, denoted by $\mathrm{T} \sim \mathrm{T}^{\prime}$, iff each element in $\mathrm{T}$ is associate to an element in $\mathrm{T}^{\prime}$ and vice versa. For a nonzero element $b$, let $E(b)$ be a complete set of distinct nonassociate divisors of $\mathrm{b}$ in $\mathrm{S}$. Then, $\mathrm{E}(\mathrm{a}) \cap \mathrm{E}(\mathrm{b}) \sim \mathrm{E}((\mathrm{a}, \mathrm{b}))$ and $\mathrm{E}\left(\mathrm{p}^{\mathrm{m}}\right) \sim\left\{1, \mathrm{p}^{1}, \mathrm{p}^{2}, \ldots, \mathrm{p}^{\mathrm{m}}\right\}$. Note that if $\mathrm{t} \sim \mathrm{t}^{\prime}$, then $\mathrm{q}(\mathrm{t})=\mathrm{q}\left(\mathrm{t}^{\prime}\right)$ and $\varphi_{\mathrm{s}}(\mathrm{t})=\varphi_{\mathrm{s}}\left(\mathrm{t}^{\prime}\right)$. Also, $\sum_{\mathrm{d} \in \mathrm{T}} \phi_{\mathrm{S}}(\mathrm{d})=\sum_{\mathrm{d} \in \mathrm{T}^{\prime}} \phi_{\mathrm{S}}(\mathrm{d})$ whenever $\mathrm{T} \sim \mathrm{T}^{\prime}$.

Theorem 1: Let $\mathrm{S}$ be a PID and let $\mathrm{b}$ be a nonzero element in $\mathrm{S}$. If $\mathrm{E}(\mathrm{b})$ is a complete set of distinct nonassociate divisors of $\mathrm{b}$, then $\mathrm{q}(\mathrm{b})=\sum_{\mathrm{d} \in \mathrm{E}(\mathrm{b})} \phi_{\mathrm{S}}(\mathrm{d})$.

Proof: Let $b \neq 0$. The result is true when $b$ is a unit. Suppose that $b$ is a nonunit so that $b=u_{1}^{\alpha_{1}} p_{2}^{\alpha_{2}} \ldots p_{i}^{\alpha_{1}}$. Since $\varphi_{\mathrm{s}}$ is multiplicative, the function $\mathrm{f}(\mathrm{b})=\sum_{\mathrm{d} \in \mathrm{E}(\mathrm{b})} \varphi_{\mathrm{S}}(\mathrm{d})$ is also multiplicative. For any prime element $p_{j}$, (1) gives:

$$
\begin{aligned}
f\left(p_{j}^{n}\right)= & \sum_{d \in E\left(p_{j}^{n}\right)} \varphi_{S}(d)=\varphi_{S}\left(p_{j}^{0}\right)+\varphi_{S}\left(p_{j}^{1}\right)+\ldots+\varphi_{S}\left(p_{j}^{n}\right) \\
= & 1+\left(q\left(p_{j}\right)-1\right)+\left(q\left(p_{j}\right)-1\right)\left(q\left(p_{j}\right)\right)+\ldots+\left(q\left(p_{j}\right)-1\right) \\
& \left(q\left(p_{j}\right)\right)^{n-1} \\
= & \left(q\left(p_{j}\right)\right)^{n}=q\left(p_{j}^{n}\right)
\end{aligned}
$$


By the multiplicativity of $\mathrm{f}(\mathrm{b})$, we have $\mathrm{q}(\mathrm{b})=\sum_{\mathrm{d} \in \mathrm{E}(\mathrm{b})} \varphi_{\mathrm{S}}(\mathrm{d})$.

Corollary 1: (Euler's) If $\mathrm{n}$ is a positive integer, then $\mathrm{n}=\sum_{\mathrm{d}>0, \mathrm{~d} \mid \mathrm{n}} \varphi(\mathrm{d})$.

\section{RESULTS}

GCD matrices on FC sets in a PID: Throughout the following, we consider $T=\left\{t_{1}, t_{2}, \ldots, t_{n}\right\}$ to be a $q-$ ordered set of nonzero nonassociate elements of a PID $S$ Define the GCD matrix on $S$ to be the $n \times n$ matrix $[T]=\left(t_{i j}\right)=q\left(\left(t_{i}, t_{j}\right)\right)$. The set $T$ is said to be a factorclosed (FC) in $S$ iff $t_{i} \in T$ and $d \mid t_{i}$ implies that $d \sim t_{j}$ for some $t_{j} \in T$. Note that any set $T$ in $S$ is either factorclosed or it is contained in a factor-closed set $\mathrm{D}$.

Theorem 2: The GCD matrix [T] can be decomposed into a product of an $n \times m$ matrix $A$ and an $m \times n$ matrix $B$, for some $m \geq n$. The nonzero entries of $A$ are equal to $\varphi_{s}(d)$ for some $d$ in a FC set D containing $\mathrm{T}$ and $\mathrm{B}$ is an incidence matrix.

Proof: Let $\mathrm{D}=\left\{\mathrm{d}_{1}, \mathrm{~d}_{2}, \ldots, \mathrm{d}_{\mathrm{m}}\right\}$ be a FC set containing $\mathrm{T}$ in the PID $S$ Define the $n \times m$ matrix $A=\left(a_{i j}\right)$ by $a_{i j}=\left\{\begin{array}{cc}\varphi_{s}\left(d_{j}\right) & \text { if } d_{j} \in E\left(t_{i}\right) \\ 0 & \text { otherwise }\end{array}\right.$ and let $B=\left(b_{i j}\right)$ be the incidence matrix corresponding to the transpose of $\mathrm{A}$, where $b_{i j}=\left\{\begin{array}{ll}1 & \text { if } a_{j i} \neq 0 \\ 0 & \text { if } a_{j i}=0\end{array}\right.$. Hence, the product $A B$ is given by:

$$
\begin{aligned}
& (A B)_{i j}=\sum_{k=1}^{n} a_{i k} b_{k j}=\sum_{\substack{d_{k} \in E\left(t_{i}\right) \\
d_{k} \in E}} \varphi_{s}\left(d_{k}\right)=\sum_{d_{k} \in E\left(t_{i}\right) \cap E\left(t_{j}\right)} \varphi_{s}\left(d_{k}\right)= \\
& \sum_{\left.d_{k} \in E\left(t_{i}, t_{j}\right)\right)} \varphi_{s}\left(d_{k}\right)=q\left(\left(t_{i}, t_{j}\right)\right)
\end{aligned}
$$

Example 1: Let $\mathrm{T}=\left\{1,1+\mathrm{x}, 1+\mathrm{x}^{3},(1+\mathrm{x})^{3}\right\}$ in $\mathrm{Z}_{2}[\mathrm{x}]$. Then $[\mathrm{T}]=\left[\begin{array}{llll}1 & 1 & 1 & 1 \\ 1 & 2 & 2 & 2 \\ 1 & 2 & 8 & 2 \\ 1 & 2 & 2 & 8\end{array}\right]$. Let $\mathrm{D}=\left\{1,1+\mathrm{x},(1+\mathrm{x})^{2}\right.$, $\left.1+\mathrm{x}+\mathrm{x}^{2}, 1+\mathrm{x}^{3},(1+\mathrm{x})^{3}\right\}$. Then, $[\mathrm{T}]_{4 \times 4}=\mathrm{A}_{4 \times 6} \cdot \mathrm{B}_{6 \times 4}$ where:

$$
A=\left[\begin{array}{llllll}
1 & 0 & 0 & 0 & 0 & 0 \\
1 & 1 & 0 & 0 & 0 & 0 \\
1 & 1 & 0 & 3 & 3 & 0 \\
1 & 1 & 2 & 0 & 0 & 4
\end{array}\right] \text { and } B=\left[\begin{array}{llll}
1 & 1 & 1 & 1 \\
0 & 1 & 1 & 1 \\
0 & 0 & 0 & 1 \\
0 & 0 & 1 & 0 \\
0 & 0 & 1 & 0 \\
0 & 0 & 0 & 1
\end{array}\right]
$$

Example 2: Let $\mathrm{T}=\{1,2,5\}$. In $\mathrm{Z}[\mathrm{i}],[\mathrm{T}]=\left[\begin{array}{ccc}1 & 1 & 1 \\ 1 & 4 & 1 \\ 1 & 1 & 25\end{array}\right]$.

Note that $\mathrm{T}$ is not $\mathrm{FC}$ in $\mathrm{Z}[\mathrm{i}]$. Select $\mathrm{D}=\{1,1+\mathrm{i}, 2,2+\mathrm{i}$, $1+2 \mathrm{i}, \quad 5\}$. Then $A=\left[\begin{array}{cccccc}1 & 0 & 0 & 0 & 0 & 0 \\ 1 & 1 & 2 & 0 & 0 & 0 \\ 1 & 0 & 0 & 4 & 4 & 16\end{array}\right] \quad$ and $\mathrm{B}=\left[\begin{array}{lll}1 & 1 & 1 \\ 0 & 1 & 0 \\ 0 & 1 & 0 \\ 0 & 0 & 1 \\ 0 & 0 & 1 \\ 0 & 0 & 1\end{array}\right]$.

Theorem 3: The GCD matrix [T] is the product of an $\mathrm{n} \times \mathrm{m}$ matrix $\mathrm{A}$ and its transpose $\mathrm{A}^{\mathrm{T}}$. The nonzero entries of $A$ are of the form $\sqrt{\varphi_{S}(d)}$ for some $d$ in a FC set D containing $\mathrm{T}$.

Proof: Let $\mathrm{D}=\left\{\mathrm{d}_{1}, \mathrm{~d}_{2}, \ldots, \mathrm{d}_{\mathrm{m}}\right\}$ be a FC set containing $\mathrm{T}$. Define the $\mathrm{n} \times \mathrm{m}$ matrix $\mathrm{A}=\left(\mathrm{a}_{\mathrm{ij}}\right)$ by $a_{i j}=\left\{\begin{array}{cc}\sqrt{\varphi_{s}\left(d_{j}\right)} & \text { if } d_{j} \in E\left(t_{i}\right) \\ 0 & \text { otherwise }\end{array}\right.$. Hence, the product $A A^{T}$ is given by:

$$
\begin{aligned}
& \left(A^{T}\right)_{i j}=\sum_{k=1}^{n} a_{i k} b_{k j}=\sum_{\substack{d_{k} \in E\left(t_{i}\right) \\
d_{k} \in E\left(t_{i}\right)}} \sqrt{\varphi_{s}\left(d_{k}\right)} \sqrt{\varphi_{s}\left(d_{k}\right)} \\
& =\sum_{d_{k} \in E\left(t_{i}\right) \cap E\left(t_{j}\right)} \varphi_{s}\left(d_{k}\right)=\sum_{\left.d_{k} \in E\left(t_{i}, t_{j}\right)\right)} \varphi_{s}\left(d_{k}\right)=q\left(\left(t_{i}, t_{j}\right)\right)
\end{aligned}
$$

Note that Theorem 2 and 3 hold even if $\mathrm{T}$ is not qordered. In the case when both $\mathrm{T}$ and $\mathrm{D}$ are q-ordered, $\mathrm{B}$ becomes in raw-echelon form.

Corollary 2: (Smith's Determinant over a PID) If $T$ is $\mathrm{FC}$ in $\mathrm{S}$, then $\operatorname{det}[\mathrm{T}]=\prod_{\mathrm{i}=1}^{\mathrm{n}} \varphi_{\mathrm{S}}\left(\mathrm{t}_{\mathrm{i}}\right)$.

Proof: Let T be a FC set. Choose $\mathrm{D}$ to be q-ordered and $\mathrm{D} \sim \mathrm{T}$. From Theorem 2, the GCD matrix $[\mathrm{T}]=\mathrm{AB}$, where $A$ is an $n \times n$ lower triangular matrix and $B$ is an upper triangular matrix such that $\mathrm{a}_{\mathrm{ii}}=\varphi_{\mathrm{s}}\left(\mathrm{t}_{\mathrm{i}}\right)$ and $\mathrm{b}_{\mathrm{ii}}=1,1$ $\leq \mathrm{i} \leq \mathrm{n}$. Therefore, $\operatorname{det}[\mathrm{T}]=\operatorname{det}[\mathrm{AB}]=\operatorname{det}[\mathrm{A}] \operatorname{det}[\mathrm{B}]=$ $\varphi_{\mathrm{S}}\left(\mathrm{t}_{1}\right) \varphi_{\mathrm{S}}\left(\mathrm{t}_{2}\right) \ldots \varphi_{\mathrm{S}}\left(\mathrm{t}_{\mathrm{n}}\right)$.

We note that if $T^{\prime}=\left\{t_{i_{1}}, t_{i_{2}}, \ldots, t_{i_{n}}\right\}$ is any arrangement of the elements of $T=\left\{t_{1}, t_{2}, \ldots, t_{n}\right\}$ in $S$, then $\operatorname{det}[\mathrm{T}]=\operatorname{det}\left[\mathrm{T}^{\prime}\right]$. This can be verified as follows. 
The matrix $[\mathrm{T}]$ can be obtained from $\left[\mathrm{T}^{\prime}\right]$ by switching the rows and the columns of $\left[\mathrm{T}^{\prime}\right]$. Thus, $[\mathrm{T}]=\mathrm{E}_{1} \mathrm{E}_{2} \ldots$ $E_{i}\left[T^{\prime}\right]$, where the $E_{j}^{\prime}$ s are elementary matrices with $\operatorname{det}\left[\mathrm{E}_{\mathrm{j}}\right]= \pm 1,1 \leq \mathrm{j} \leq \mathrm{i}$. Hence, $[\mathrm{T}]$ and $\left[\mathrm{T}^{\prime}\right]$ are similar matrices and $\operatorname{det}[\mathrm{T}]=\operatorname{det}\left[\mathrm{T}^{\prime}\right]$.

Next, we consider the converse of Corollary 2. Let $\mathrm{S}$ be a PID and let $\mathrm{T}=\left\{\mathrm{t}_{1}, \mathrm{t}_{2}, \ldots, \mathrm{t}_{\mathrm{n}}\right\}$ be a nonempty set of nonzero nonassociate elements in $S$ with $\operatorname{det}[\mathrm{T}]=\prod_{\mathrm{i}=1}^{\mathrm{n}} \varphi_{\mathrm{S}}\left(\mathrm{t}_{\mathrm{i}}\right) . \quad$ Is it true that $\mathrm{T}$ is factor-closed in $\mathrm{S}$ ?

Consider a minimal FC set $\mathrm{D}=\left\{\mathrm{t}_{1}, \mathrm{t}_{2}, \ldots, \mathrm{t}_{\mathrm{n}}, \mathrm{t}_{\mathrm{n}+1}, \ldots\right.$, $\left.\mathrm{t}_{\mathrm{n}+\mathrm{r}}\right\}$ containing $\mathrm{T}=\left\{\mathrm{t}_{1}, \mathrm{t}_{2}, \ldots, \mathrm{t}_{\mathrm{n}}\right\}$ with $\mathrm{t}_{1}\left\langle\mathrm{t}_{2}\left\langle\ldots<\mathrm{t}_{\mathrm{n}}\right.\right.$ and $\mathrm{t}_{\mathrm{n}+1}<\mathrm{t}_{\mathrm{n}+2}<\ldots<\mathrm{t}_{\mathrm{n}+\mathrm{r}}$. Define an $\mathrm{n} \times(\mathrm{n}+\mathrm{r})$ matrix $A$ by $(\mathrm{A})_{\mathrm{ij}}=\varepsilon_{\mathrm{ij}} \sqrt{\varphi_{\mathrm{s}}\left(\mathrm{t}_{\mathrm{j}}\right)}$, where $\varepsilon_{\mathrm{ij}}$ is 1 if $\mathrm{t}_{\mathrm{j}} \in \mathrm{E}\left(\mathrm{t}_{\mathrm{i}}\right)$ and 0 otherwise. Denote the matrix $\left(\varepsilon_{\mathrm{ij}}\right)_{\mathrm{n} \times(\mathrm{n}+\mathrm{r})}$ by $\mathrm{E}$, a $\{0,1\}-$ matrix. Note that the matrix $A$ is the same matrix $A$ defined in Theorem 3.

For an $\mathrm{n} \times \mathrm{m}$ matrix $\mathrm{M}, \mathrm{n}>\mathrm{m}$ and any set of indices $\mathrm{k}_{1}, \mathrm{k}_{2}, \ldots, \mathrm{k}_{\mathrm{n}}$ with $1 \leq \mathrm{k}_{1}<\mathrm{k}_{2}<\ldots<\mathrm{k}_{\mathrm{n}} \leq \mathrm{m}$, let $\mathrm{M}_{\left(\mathrm{k}_{1}, \mathrm{k}_{2}, \ldots, \mathrm{k}_{\mathrm{n}}\right)}$ denote the submatrix consisting of $\mathrm{k}_{1}^{\text {th }}, \mathrm{k}_{2}^{\text {th }}$, $\ldots \mathrm{k}_{\mathrm{n}}{ }^{\text {th }}$ columns of $\mathrm{M}$.

Theorem 4: Let $D=\left\{t_{1}, t_{2}, \ldots, t_{n}, t_{n+1}, \ldots, t_{n+s}\right\}$ be a minimal FC set containing $T=\left\{t_{1}, t_{2}, \ldots, t_{n}\right\}$ in $S$, where $t_{1}<t_{2}<\ldots<t_{n}$ and $t_{n+1}<t_{n+2}<\ldots<t_{n+s}$. Then:

$$
\operatorname{det}[\mathrm{T}]=\sum_{1 \leq \mathrm{k}_{1}<\mathrm{k}_{2} \ldots<\mathrm{k}_{\mathrm{n}} \leq \mathrm{n}+\mathrm{s}}\left(\operatorname{det}\left[\mathrm{E}_{\left(\mathrm{k}_{1}, \mathrm{k}_{2}, \ldots, \mathrm{k}_{\mathrm{n}}\right)}\right]^{2}\right) \varphi_{\mathrm{s}}\left(\mathrm{t}_{\mathrm{k}_{1}}\right) \varphi_{\mathrm{s}}\left(\mathrm{t}_{\mathrm{k}_{2}}\right) . . \varphi_{\mathrm{s}}\left(\mathrm{t}_{\mathrm{k}_{\mathrm{n}}}\right)
$$

Proof: Since $[\mathrm{T}]=\mathrm{AA}^{\mathrm{T}}$, Cauchy-Binet formula gives that:

$$
\begin{aligned}
\operatorname{det}[\mathrm{T}] & =\operatorname{det}\left[\mathrm{AA}^{\mathrm{T}}\right] \\
& =\sum_{1 \leq \mathrm{k}_{1}<\mathrm{k}_{2} \ldots<\mathrm{k}_{\mathrm{n}} \leq \mathrm{n}+\mathrm{s}}\left(\operatorname{det}\left[\mathrm{A}_{\left(\mathrm{k}_{1}, \mathrm{k}_{2}, \ldots, \mathrm{k}_{\mathrm{n}}\right)}\right] \operatorname{det}\left[\mathrm{A}_{\left(\mathrm{k}_{1}, \mathrm{k}_{2}, \ldots, \mathrm{k}_{\mathrm{n}}\right)}^{\mathrm{T}}\right]\right) \\
& =\sum_{1 \leq \mathrm{k}_{1}<\mathrm{k}_{2} \ldots<\mathrm{k}_{\mathrm{n}} \leq \mathrm{n}+\mathrm{s}}\left(\operatorname{det}\left[\mathrm{A}_{\left(\mathrm{k}_{1}, \mathrm{k}_{2}, \ldots, \mathrm{k}_{\mathrm{n}}\right)}\right]^{2}\right)
\end{aligned}
$$

The result follows from the fact that:

$$
\operatorname{det}\left[\mathrm{A}_{\left(\mathrm{k}_{1}, \mathrm{k}_{2}, \ldots, \mathrm{k}_{\mathrm{n}}\right)}=\operatorname{det}\left[\mathrm{E}_{\left(\mathrm{k}_{1}, \mathrm{k}_{2}, \ldots, \mathrm{k}_{\mathrm{n}}\right)}\right] \sqrt{\varphi_{\mathrm{s}}\left(\mathrm{t}_{\mathrm{k}_{1}}\right) \varphi_{\mathrm{s}}\left(\mathrm{t}_{\mathrm{k}_{2}}\right) \ldots \varphi_{\mathrm{s}}\left(\mathrm{t}_{\mathrm{k}_{\mathrm{n}}}\right)}\right.
$$

Corollary 3: Let $[\mathrm{T}]$ be the GCD matrix defined on $\mathrm{T}$ in $S$. Then, $\operatorname{det}[T] \geq \varphi_{\mathrm{s}}\left(\mathrm{t}_{1}\right) \varphi_{\mathrm{s}}\left(\mathrm{t}_{2}\right) \ldots \varphi_{\mathrm{s}}\left(\mathrm{t}_{\mathrm{n}}\right)$.

Proof: The terms in the summation of Theorem 4 are nonnegative. Since the submatrix $\mathrm{E}_{\left(\mathrm{k}_{1}, \mathrm{k}_{2}, \ldots, \mathrm{k}_{\mathrm{n}}\right)}$ is lower triangular with diagonal elements equal to 1 , we have that the term corresponding to $\left(\mathrm{k}_{1}, \mathrm{k}_{2}, \ldots, \mathrm{k}_{\mathrm{n}}\right)=(1,2, \ldots$, $\mathrm{n})$ is $\operatorname{det}[\mathrm{E}(1,2, \ldots, \mathrm{n})]^{2} \varphi_{\mathrm{s}}\left(\mathrm{t}_{1}\right) \quad \varphi_{\mathrm{s}}\left(\mathrm{t}_{2}\right) \ldots \varphi_{\mathrm{s}}\left(\mathrm{t}_{\mathrm{n}}\right)=\varphi_{\mathrm{s}}\left(\mathrm{t}_{1}\right)$ $\varphi_{s}\left(t_{2}\right) \ldots \varphi_{s}\left(t_{n}\right)$. Therefore, $\operatorname{det}[T] \geq \varphi_{s}\left(t_{1}\right) \varphi_{s}\left(t_{2}\right) \ldots \varphi_{s}\left(t_{n}\right)$.

Theorem 5: Let [T] be the GCD matrix defined on $T$ in S. Then, $\operatorname{det}[\mathrm{T}]=\varphi_{\mathrm{s}}\left(\mathrm{t}_{1}\right) \varphi_{\mathrm{s}}\left(\mathrm{t}_{2}\right) \ldots \varphi_{\mathrm{s}}\left(\mathrm{t}_{\mathrm{n}}\right)$ if and only if $\mathrm{T}$ is factor-closed in $\mathrm{S}$.

Proof: The sufficient condition holds from Corollary 2. Conversely, suppose that $\operatorname{det}[\mathrm{T}]=\varphi_{\mathrm{s}}\left(\mathrm{t}_{1}\right) \varphi_{\mathrm{s}}\left(\mathrm{t}_{2}\right) \ldots \varphi_{\mathrm{s}}\left(\mathrm{t}_{\mathrm{n}}\right)$. For contradiction purposes, suppose that $\mathrm{T}$ is not $\mathrm{FC}$. Let $D=\left\{t_{1}, t_{2}, \ldots, t_{n}, t_{n+1}, \ldots, t_{n+s}\right\}$ be a minimal FC set containing $T$ in $S$ such that $t_{1}<t_{2}<\ldots<t_{n}$ and $t_{n+1}\left\langle t_{n+2}<\ldots\right.$ $\left\langle t_{n+s}\right.$. Since $T$ is not FC, D is not associate to $T$ in $S$. Then, $t_{n+1}$ is in $D$ but not in $T$ and $t_{n+1} \in E(t)$ for some $t$ in $T$. Now, let $t_{r}$ be the first element in $T$ such that $\mathrm{t}_{\mathrm{n}+1} \in \mathrm{E}\left(\mathrm{t}_{\mathrm{r}}\right)$. Then, the submatrix $\mathrm{A}_{(1,2, \ldots \mathrm{r}-1, \mathrm{n}+1, \mathrm{r}+1, \ldots, \mathrm{n})}$ consisting of the $1^{\text {st }}, 2^{\text {nd }}, \ldots,\left(\mathrm{r}^{-1}\right)^{\text {th }},(\mathrm{n}+1)^{\text {th }},(\mathrm{r}+1)^{\text {th }}, \ldots$ and $n^{\text {th }}$ columns of $A_{n \times(n+s)}$ is a lower triangular matrix of nonzero determinant. Hence, $\mathrm{E}_{(1,2, \ldots \mathrm{r}-1, \mathrm{n}+1, \mathrm{r}+1, \ldots, \mathrm{n})}$ is a $\{0,1\}$-matrix whose diagonal elements are equal to 1 . Since $\mathrm{E}_{(1,2, \ldots \mathrm{r}-1, \mathrm{r}+1, \ldots, \mathrm{n}, \mathrm{n}+1)}$ can be obtained from $\mathrm{E}_{(1,2, \ldots \mathrm{r}-1, \mathrm{n}+1, \mathrm{r}+1, \ldots, \mathrm{n})}$ by performing a certain numbers of successive column permutations, $\operatorname{det}\left[\mathrm{E}_{(1,2, \ldots \mathrm{r}-1, \mathrm{r}+1, \ldots, \mathrm{n}, \mathrm{n}+1)}\right]= \pm \operatorname{det}\left[\mathrm{E}_{(1,2, \ldots \mathrm{r}-1, \mathrm{n}+1, \mathrm{r}+1, \ldots, \mathrm{n})}\right]= \pm 1$.

From Theorem 4, we have:

$$
\begin{aligned}
\operatorname{det}[\mathrm{T}]= & \sum_{1 \leq \mathrm{k}_{1}<\mathrm{k}_{2} \ldots<\mathrm{k}_{\mathrm{n}} \leq \mathrm{n}+\mathrm{s}}\left(\operatorname{det}\left[\mathrm{E}_{\left(\mathrm{k}_{1}, \mathrm{k}_{2}, \ldots, \mathrm{k}_{\mathrm{n}}\right)}\right]^{2}\right) \varphi_{\mathrm{s}}\left(\mathrm{t}_{\mathrm{k}_{1}}\right) \varphi_{\mathrm{s}}\left(\mathrm{t}_{\mathrm{k}_{2}}\right) \ldots \varphi_{\mathrm{s}}\left(\mathrm{t}_{\mathrm{k}_{\mathrm{n}}}\right) \\
= & \varphi_{\mathrm{s}}\left(\mathrm{t}_{1}\right) \varphi_{\mathrm{s}}\left(\mathrm{t}_{2}\right) \ldots \varphi_{\mathrm{s}}\left(\mathrm{t}_{\mathrm{n}}\right)+\varphi_{\mathrm{s}}\left(\mathrm{t}_{1}\right) \varphi_{\mathrm{s}}\left(\mathrm{t}_{2}\right) \ldots \varphi_{\mathrm{s}}\left(\mathrm{t}_{\mathrm{r}-1}\right) \varphi_{\mathrm{s}}\left(\mathrm{t}_{\mathrm{r}+1}\right) \\
& \ldots \varphi_{\mathrm{s}}\left(\mathrm{t}_{\mathrm{n}}\right) \varphi_{\mathrm{s}}\left(\mathrm{t}_{\mathrm{n}+1}\right)+\ldots>\varphi_{\mathrm{s}}\left(\mathrm{t}_{1}\right) \varphi_{\mathrm{s}}\left(\mathrm{t}_{2}\right) \ldots \varphi_{\mathrm{s}}\left(\mathrm{t}_{\mathrm{n}}\right)
\end{aligned}
$$

This contradicts the necessary condition that the equality holds.

Inverses of GCD matrices in a PID: Let $\mathrm{t}$ be any nonzero element in $\mathrm{S}$. The generalized Mobius function over $\mathrm{S}$ is defined by:

$$
\mu_{s}(t)=\left\{\begin{array}{cc}
1 & \text { if } t \text { is a unit } \\
(-1)^{\mathrm{m}} & \text { if } \mathrm{t} \text { is the product of } \mathrm{m} \text { nonassociate primes } \\
0 & \text { otherwise }
\end{array}\right.
$$

Note that:

$$
\sum_{\mathrm{d} \in \mathrm{E}(\mathrm{t})} \mu_{\mathrm{s}}(\mathrm{d})=\left\{\begin{array}{lc}
1 & \text { if tis a unit } \\
0 & \text { otherwise }
\end{array}\right.
$$

Corollary 4: Let $[\mathrm{T}]$ be the GCD matrix defined on $\mathrm{T}$ in S. Then, $[\mathrm{T}]$ is invertible and its inverse $[\mathrm{T}]^{-1}=\left(\mathrm{r}_{\mathrm{ij}}\right)$ is given by: 


$$
\mathrm{r}_{\mathrm{ij}}=\sum_{\substack{\mathrm{t}_{\mathrm{i}} \in \mathrm{E}\left(\mathrm{t}_{\mathrm{t}}\right) \\ \mathrm{t}_{\mathrm{j}} \in \mathrm{E}\left(\mathrm{t}_{\mathrm{k}}\right)}} \frac{1}{\varphi_{\mathrm{s}}\left(\mathrm{t}_{\mathrm{k}}\right)} \mu_{\mathrm{s}}\left(\mathrm{t}_{\mathrm{k}} / \mathrm{t}_{\mathrm{i}}\right) \mu_{\mathrm{s}}\left(\mathrm{t}_{\mathrm{k}} / \mathrm{t}_{\mathrm{j}}\right)
$$

Proof: Define the $n \times n$ matrices $E=\left(e_{i j}\right)$ and $\mathrm{U}=\left(\mathrm{u}_{\mathrm{ij}}\right)$ as follows: $\mathrm{e}_{\mathrm{ij}}=\left\{\begin{array}{cc}1 & \text { if } \mathrm{t}_{\mathrm{i}} \in \mathrm{E}\left(\mathrm{t}_{\mathrm{j}}\right) \\ 0 & \text { otherwise }\end{array}\right.$ and $\mathrm{u}_{\mathrm{ij}}=\left\{\begin{array}{cc}\mu_{\mathrm{s}}\left(\mathrm{t}_{\mathrm{i}} / \mathrm{t}_{\mathrm{j}}\right) & \text { if } \mathrm{t}_{\mathrm{i}} \in \mathrm{E}\left(\mathrm{t}_{\mathrm{j}}\right) \\ 0 & \text { otherwise }\end{array} . \quad\right.$ Then, $\quad(E U)_{\mathrm{ij}}=\sum_{\mathrm{k}=1}^{\mathrm{n}} \mathrm{e}_{\mathrm{ik}} \mathrm{u}_{\mathrm{kj}}=$ $\sum_{\mathrm{t}_{\mathrm{j}} \in \mathrm{E}\left(\mathrm{t}_{\mathrm{k}}\right)} \mu_{\mathrm{s}}\left(\mathrm{t}_{\mathrm{i}} / \mathrm{t}_{\mathrm{j}}\right)=\sum_{\mathrm{t}_{\mathrm{k}} \in \mathrm{E}\left(\mathrm{t}_{\mathrm{i}} / \mathrm{t}_{\mathrm{j}}\right)} \mu_{\mathrm{s}}\left(\mathrm{t}_{\mathrm{k}}\right)=\left\{\begin{array}{cc}1 & \text { if } \mathrm{t}_{\mathrm{i}} \sim \mathrm{t}_{\mathrm{j}} \\ 0 & \text { otherwise }\end{array}\right.$. The last equality follows from (3). Since the elements in $\mathrm{T}$ are nonassociate, we have $\mathrm{U}=\mathrm{E}^{-1}$. If $\mathrm{D}$ is the diagonal matrix $\operatorname{diag}\left(\varphi_{\mathrm{s}}\left(\mathrm{t}_{1}\right), \quad \varphi_{\mathrm{s}}\left(\mathrm{t}_{2}\right), \ldots, \varphi_{\mathrm{s}}\left(\mathrm{t}_{\mathrm{n}}\right)\right)$ and $\mathrm{A}=\mathrm{ED}^{1 / 2}$, then $[\mathrm{T}]=\mathrm{AA}^{\mathrm{T}}=\left(\mathrm{ED}^{1 / 2}\right)\left(\mathrm{ED}^{1 / 2}\right)^{\mathrm{T}}=\mathrm{EDE}^{\mathrm{T}}$. Therefore, $[\mathrm{T}]^{-1}=\mathrm{U}^{\mathrm{T}} \mathrm{D}^{-1} \mathrm{U}=\left(\mathrm{r}_{\mathrm{ij}}\right)$, where $\mathrm{r}_{\mathrm{ij}}=\left(\mathrm{U}^{\mathrm{T}} \mathrm{D}^{-1} \mathrm{U}\right)_{\mathrm{ij}}=$ $\sum_{\mathrm{k}=1}^{\mathrm{n}} \frac{1}{\varphi_{\mathrm{s}}\left(\mathrm{t}_{\mathrm{k}}\right)} \mathrm{u}_{\mathrm{ki}} \mathrm{u}_{\mathrm{kj}}=\sum_{\substack{\left.\mathrm{t}_{\mathrm{i}} \in \mathrm{t}_{\mathrm{k}}\right) \\ \mathrm{t}_{\mathrm{j}} \in \mathrm{E}\left(\mathrm{t}_{\mathrm{k}}\right)}} \frac{1}{\varphi_{\mathrm{s}}\left(\mathrm{t}_{\mathrm{k}}\right)} \mu_{\mathrm{s}}\left(\mathrm{t}_{\mathrm{k}} / \mathrm{t}_{\mathrm{i}}\right) \mu_{\mathrm{s}}\left(\mathrm{t}_{\mathrm{k}} / \mathrm{t}_{\mathrm{j}}\right)$.

Example 3: Let $\mathrm{S}=\mathrm{Z}_{2}[\mathrm{x}]$ and let $\mathrm{T}=\left\{1,1+\mathrm{x}, 1+\mathrm{x}^{2}\right.$, $\left.(1+x)^{3}, 1+x+x^{2}\right\}$, which is a q-ordered FC set of nonzero nonassociate elements in $Z_{2}[x]$. Then, $[\mathrm{T}]=\left[\begin{array}{lllll}1 & 1 & 1 & 1 & 1 \\ 1 & 2 & 2 & 2 & 1 \\ 1 & 2 & 4 & 4 & 1 \\ 1 & 2 & 4 & 8 & 1 \\ 1 & 1 & 1 & 1 & 4\end{array}\right]$. By corollary $4,[\mathrm{~T}]^{-1}$ is obtained as follows:

$$
\begin{aligned}
& \mathrm{a}_{11}=\frac{1}{\varphi_{\mathrm{S}}(1)}+\frac{1}{\varphi_{\mathrm{S}}(1+\mathrm{x})}+\frac{1}{\varphi_{\mathrm{S}}\left(1+\mathrm{x}+\mathrm{x}^{2}\right)}=1+1+\frac{1}{3}=\frac{7}{3} \\
& \mathrm{a}_{12}=\frac{-1}{\varphi_{\mathrm{S}}(1+\mathrm{x})}=-1 \\
& \mathrm{a}_{13}=\mathrm{a}_{14}=0, \mathrm{a}_{12}=\frac{-1}{\varphi_{\mathrm{S}}\left(1+\mathrm{x}+\mathrm{x}^{2}\right)}=\frac{-1}{3}
\end{aligned}
$$

and so forth. Therefore:

$$
[\mathrm{T}]^{-1}=\left[\begin{array}{ccccc}
7 / 3 & -1 & 0 & 0 & -1 / 3 \\
-1 & 3 / 2 & -1 / 2 & 0 & 0 \\
0 & -1 / 2 & 3 / 4 & -1 / 4 & 0 \\
0 & 0 & -1 / 4 & 1 / 4 & 0 \\
-1 / 3 & 0 & 0 & 0 & 1 / 3
\end{array}\right]
$$

Reciprocal GCD Matrices in a PID: The reciprocal GCD matrix on $\mathrm{T}$ in $\mathrm{S}$ is the $\mathrm{n} \times \mathrm{n}$ matrix $1 /[\mathrm{T}]$ whose $(\mathrm{i}, \mathrm{j})$-entry is $1 / \mathrm{q}\left(\left(\mathrm{t}_{\mathrm{i}}, \mathrm{t}_{\mathrm{j}}\right)\right)$. It is clear that $1 /[\mathrm{T}]$ is symmetric. Furthermore, permutations of the elements of $\mathrm{T}$ yield similar reciprocal GCD matrices. For a nonzero element $\mathrm{t}$ in $\mathrm{T}$, define the function $\xi$ by $\xi(t)=\frac{1}{q(t)} \sum_{d \in E(t)} q(d) \mu_{s}(d)$. A generalized version of the Mobius inversion formula can be used to show that $\frac{1}{\mathrm{q}(\mathrm{t})}=\sum_{\mathrm{d} \in \mathrm{E}(\mathrm{t})} \xi(\mathrm{d})$. Since $\xi(\mathrm{t})$ is the product of two multiplicative functions $\frac{1}{\mathrm{q}(\mathrm{t})}$ and $\chi(\mathrm{t})=\sum_{\mathrm{d} \in \mathrm{E}(\mathrm{t})} \mathrm{q}(\mathrm{d}) \mu_{\mathrm{s}}(\mathrm{d})$, we have that $\xi(t)$ is itself multiplicative. Moreover, if $\mathrm{p}$ is prime in $\mathrm{S}$, then $\chi\left(\mathrm{p}^{\mathrm{n}}\right)=\tilde{1} \mathrm{q}(\mathrm{p})$. Hence, $\xi\left(\mathrm{p}^{\mathrm{n}}\right)=\frac{1-\mathrm{q}(\mathrm{p})}{(\mathrm{q}(\mathrm{p}))^{\mathrm{n}}}$. Therefore:

$\xi(t)=\frac{1}{q(t)} \prod_{p \in E(t)}(1-q(p))=\frac{\varphi_{S}(t)}{(q(t))^{2}} \prod_{p \in E(t)}(-q(p))$

where, the product runs over all prime divisors $\mathrm{p}$ of $\mathrm{t}$ in $\mathrm{E}(\mathrm{t})$.

In the following two theorems we obtain two factorizations for the reciprocal GCD matrices.

Theorem 6: Let $D=\left\{d_{1}, d_{2}, \ldots, d_{m}\right\}$ be a FC set containing $\mathrm{T}$ in $\mathrm{S}$. The reciprocal GCD matrix defined on $\mathrm{T}$ is the product of an $\mathrm{n} \times \mathrm{m}$ matrix $\mathrm{A}=\left(\mathrm{a}_{\mathrm{ij}}\right)$, defined by $a_{i j}=\left\{\begin{array}{cc}\xi\left(d_{j}\right) & \text { if } d_{j} \in E\left(t_{i}\right) \\ 0 & \text { otherwise }\end{array}\right.$ and an $m \times n$ incidence matrix B corresponding to $\mathrm{A}^{\mathrm{T}}$.

Proof: Let $A$ be as defined and let $B$ be the $m \times n$ matrix with $b_{i j}=\left\{\begin{array}{ll}1 & \text { if } a_{i j} \neq 0 \\ 0 & \text { if } a_{i j}=0\end{array}\right.$. Then:

$$
\begin{aligned}
& (A B)_{i j}=\sum_{k=1}^{m} a_{i k} b_{k j}=\sum_{\substack{d_{j} \in E\left(t_{i}\right) \\
d_{j} \in E\left(t_{j}\right)}} \xi\left(d_{j}\right)=\sum_{d_{j} \in E\left(t_{i}\right) \cap E\left(t_{j}\right)} \xi\left(d_{j}\right) \\
& =\sum_{\left.d_{j} \in E\left(t_{i}, t_{j}\right)\right)} \xi\left(d_{j}\right)=\frac{1}{q\left(\left(t_{i}, t_{j}\right)\right)}
\end{aligned}
$$

In a similar manner we prove the second factorization given in the following theorem.

Theorem 7: Let $D=\left\{d_{1}, d_{2}, \ldots, d_{m}\right\}$ be a FC set containing $\mathrm{T}$ in $\mathrm{S}$ and let $\mathrm{C}$ be the the $\mathrm{n} \times \mathrm{n}$ matrix given by $a_{i j}=\left\{\begin{array}{cc}\sqrt{\xi\left(d_{j}\right)} & \text { if } d_{j} \in E\left(t_{i}\right) \\ 0 & \text { otherwise }\end{array}\right.$. Then $1 /[T]=C C^{T}$.

The proof of the following theorem is similar to those of Theorems 4 and 5. 
Theorem 8: Let $T$ be a set in $S$. Then, $\operatorname{det}(1 /[T])=$ $\xi\left(\mathrm{t}_{1}\right) \xi\left(\mathrm{t}_{2}\right) \ldots \xi\left(\mathrm{t}_{\mathrm{n}}\right)$ iff $\mathrm{T}$ is factor-closed in $\mathrm{S}$.

LCM Matrices on FC Sets in a PID: The least common multiple (LCM) matrix defined on $\mathrm{T}$ in $\mathrm{S}$ is the $n \times n$ matrix $[[T]]=\left(t_{i j}\right)$, where $t_{i j}=q\left(\left[t_{i}, t_{j}\right]\right)$ and $\left[t_{i}\right.$, $t_{j}$ ] is the least common multiple of $t_{i}$ and $t_{j}$ in $S$.

Theorem 9: If $T$ is $F C$ in $S$, then
$\operatorname{det}[[T]]=\prod_{i=1}^{n}\left(\varphi_{S}\left(t_{i}\right) \prod_{p \in E\left(t_{i}\right)}(-q(p))\right)$.

Proof: Since $\left[\mathrm{t}_{\mathrm{i}}, \mathrm{t}_{\mathrm{j}}\right] \sim\left(\mathrm{t}_{\mathrm{i}} \mathrm{t}_{\mathrm{j}}\right) /\left(\mathrm{t}_{\mathrm{j}} \mathrm{t}_{\mathrm{j}}\right)$, we have and $\mathrm{q}\left(\left[\mathrm{t}_{\mathrm{i}}\right.\right.$, $\left.\left.\mathrm{t}_{\mathrm{j}}\right]\right)=\mathrm{q}\left(\mathrm{t}_{\mathrm{i}}\right) \mathrm{q}\left(\mathrm{t}_{\mathrm{j}}\right) / \mathrm{q}\left(\left(\mathrm{t}_{\mathrm{j}} \mathrm{t}_{\mathrm{j}}\right)\right)$. Now $\mathrm{q}\left(\mathrm{t}_{\mathrm{i}}\right)$ can be factored out from the $i^{\text {th }}$ row and $q\left(t_{j}\right)$ from the $j^{\text {th }}$ column to obtain $1 /[T]$. Hence, $[[T]]=$ D. $(1 /[T]) \cdot D$, where $D$ is the $n \times n$ diagonal matrix with diagonal entries $\mathrm{q}\left(\mathrm{t}_{1}\right), \mathrm{q}\left(\mathrm{t}_{2}\right), \ldots$, $\mathrm{q}\left(\mathrm{t}_{\mathrm{n}}\right)$. From 4, we have that:

$$
\begin{aligned}
\operatorname{det}[[\mathrm{S}]] & =\operatorname{det}(\mathrm{D} \cdot(1 /[\mathrm{T}]) \cdot \mathrm{D})=\operatorname{det}(\mathrm{D})^{2} \operatorname{det}(1 /[\mathrm{T}]) \\
& =\left(\mathrm{q}\left(\mathrm{t}_{1}\right)\right)^{2}\left(\mathrm{q}\left(\mathrm{t}_{2}\right)\right)^{2} \ldots\left(\mathrm{q}\left(\mathrm{t}_{\mathrm{n}}\right)\right)^{2} \xi\left(\mathrm{t}_{1}\right) \xi\left(\mathrm{t}_{2}\right) \ldots \xi\left(\mathrm{t}_{\mathrm{n}}\right) \\
& =\prod_{\mathrm{i}=1}^{\mathrm{n}}\left(\varphi_{\mathrm{S}}\left(\mathrm{t}_{\mathrm{i}}\right) \prod_{\mathrm{p} \in \mathrm{E}\left(\mathrm{t}_{\mathrm{i}}\right)}(-\mathrm{q}(\mathrm{p}))\right)
\end{aligned}
$$

Cauchy Binet formula yields a formula for the determinant of the LCM matrix defined on a set T which is not necessarily FC. The formula is given by:

$$
\begin{aligned}
& \operatorname{det}[[\mathrm{T}]]=\sum_{1 \leq \mathrm{k}_{1}<\mathrm{k}_{2} \ldots<\mathrm{k}_{\mathrm{n}} \leq \mathrm{n}+\mathrm{s}} \operatorname{det}\left(\mathrm{E}_{\left(\mathrm{k}_{1}, \mathrm{k}_{2}, \ldots, \mathrm{k}_{\mathrm{n}}\right)}\right)^{2} \\
& \left(\mathrm{q}\left(\mathrm{t}_{\mathrm{k}_{1}}\right) \mathrm{q}\left(\mathrm{t}_{\mathrm{k}_{2}}\right) \ldots \mathrm{q}\left(\mathrm{t}_{\mathrm{k}_{\mathrm{n}}}\right)\right)^{2} \xi\left(\mathrm{t}_{\mathrm{k}_{1}}\right) \xi\left(\mathrm{t}_{\mathrm{k}_{2}}\right) \ldots \xi\left(\mathrm{t}_{\mathrm{k}_{\mathrm{n}}}\right)
\end{aligned}
$$

From Theorem 9, we have that the determinant of the GCD matrix on $\mathrm{S}$ divides the determinant of the LCM matrix whenever T is FC in S.

\section{DISCUSSION}

Most of the existing results related to GCD and LCM matrices are obtained in the domain of natural integers. The results are based on certain number theoretic functions such as Euler's phi function and the Mobius function. These function and their properties can be generalized to principal ideal domains. By describing the underlying computational procedures and the various properties in the new settings, the existing results related to GCD and LCM defined on factor closed sets are extended to PIDs. This provides a large class of such matrices where many new examples can be constructed. In particular, examples in the domains of Gaussian integers and the ring of polynomials over a finite field may give new insight to some open problems.

\section{CONCLUSION}

The extension of the GCD and LCM matrices to PIDs provide a lager class for such matrices. Many of the open problems can be investigated in the new settings. For future study, we suggest the problem of extending GCD and LCM matrices defined on gcd closed sets to PIDS.

\section{REFRENCES}

1. Beslin, S., 1991. Reciprocal GCD matrices and LCM matrices. Fibonacci Q., 29: 271-274. http://www.engineering.sdstate.edu/ fib/fibprevious.html

2. Beslin, S. and N. el-Kassar, 1989. GCD matrices and Smith's determinant for a UFD. Bull. Number Theor. Relat. Top., 13: 17-22.

http://www.ams.org/mathscinet/search/publications .$h t m l$ ?pg1=ISSI\&s1=116451

3. Beslin, S. and S. Ligh 1989. Greatest common divisor matrices. Linear Algebra Applied, 118: 69-76. DOI: 10.1016/0024-3795(89)90572-7

4. Beslin, S. and S. Ligh, 1989. Another generalization of Smith's determinant. Bull. Aust. Math. Soc., 40: 413-415.

http://journals.cambridge.org/action/displayJournal ?jid=BAZ

5. Beslin, S. and S. Ligh, 1992. GCD closed sets and the determinants of GCD matrices. Fibonacci Q., 30: 157-160.

http://www.engineering.sdstate.edu/ fib/fibprevious.html

6. Borque, K. and S. Ligh, 1992. On GCD and LCM matrices. Linear Algebra Applied, 174: 65-74. DOI: 10.1016/0024-3795(92)90042-9

7. Borque, K. and S. Ligh, 1993. Matrices associated with classes of arithmetical functions. J. Number Theor., 45: 367-376. DOI: 10.1006/jnth.1993.1083

8. Borque, K. and S. Ligh, 1993. Matrices associated with arithmetical functions. Linear Multilinear Algebra, 34: 261-267. DOI: 10.1080/03081089308818225

9. Haukkanen, P., J. Wang and J. Sillanpaa, 1997. On Smith's determinant. Linear Algebra Applied, 258: 251-269. DOI: $10.1016 / \mathrm{S} 0024-$ 3795(96)00192-9

10. Li, Z., 1990. The determinants of GCD matrices. Linear Algebra Applied, 134: 137-143. DOI: 10.1016/0024-3795(90)90012-2

11. Smith, H.J.S., 1876. On the value of a certain arithmetical determinant. Proc. Lond. Math. Soc., 7: 208-212. DOI: 10.1112/plms/s1-7.1.208 